\title{
AN EXTENSION OF A THEOREM ON THE EQUIVALENCE BETWEEN ABSOLUTE RIESZIAN AND ABSOLUTE CESÀRO SUMMABILITY
}

\section{by D. BORWEIN}

(Received 5th January, 1959; and in revised form, 11th February 1959)

1. Introduction. Let $\sum_{n=0}^{\infty} a_{n}$ be a given series and let

$$
C_{n}^{(k)}=\left(\begin{array}{c}
n+k \\
n
\end{array}\right)^{-1} \sum_{r=0}^{n}\left(\begin{array}{c}
n-r+k \\
n-r
\end{array}\right) a_{r}, \quad C_{k}(w)=w^{-k} \sum_{n<w}(w-n)^{k} a_{n} .
$$

With Flett [4], we say that the series is summable $|C, k, q|_{p}, k>-1, p \geqslant 1, q$ real, if

$$
\sum_{n=1}^{\infty} n^{p q+p-1}\left|\Delta C_{n}^{(k)}\right|^{p}<\infty
$$

where $\Delta C_{n}^{(k)}=C_{n}^{(k)}-C_{n-1}^{(k)}$. Summability $|C, k, 0|_{1}$ is identical with absolute Cesàro summability $(C, k)$, or summability $|C, k|$, as defined by Fekete [3].

Absolute Rieszian summability $(R, k)$, or summability $|R, k|$, has been defined by Obreschkoff $[5,6]$ as follows: $\Sigma a_{n}$ is summable $|R, k|, k>0$, if

$$
\int_{1}^{\infty}\left|\frac{d}{d u} C_{k}(u)\right| d u<\infty
$$

It is therefore natural to say that $\Sigma a_{n}$ is summable $|R, k, q|_{p}, k>0, p \geqslant 1$, if

$$
\int_{1}^{\infty} u^{p q+p-1}\left|\frac{d}{d u} C_{k}(u)\right|^{p} d u<\infty .
$$

For this definition to be valid it is necessary to impose the additional restriction $k>1-1 / p$, as can be seen from the following argument (cf. Boyd and Hyslop [1, 94-5]).

Let $2 \leqslant n<u<n+1$, where $n$ is an integer such that $a_{n} \neq 0$. Then, for $k>0, p \geqslant 1$,

$$
\begin{aligned}
\left|\frac{d}{d u} C_{k}(u)\right|=k u^{-k-1} \mid & \sum_{r=1}^{n}(u-r)^{k-1} r a_{r} \mid \\
& \geqslant k u^{-k-1}(u-n)^{k-1} n\left|a_{n}\right|-k u^{-k-1}\left|\sum_{r=1}^{n-1}(u-r)^{k-1} r a_{r}\right|,
\end{aligned}
$$

so that

$$
\begin{aligned}
2^{p} \int_{n}^{n+1} u^{p q+p-1}\left|\frac{d}{d u} C_{k}(u)\right|^{p} d u & \geqslant(k n)^{p}\left|a_{n}\right|^{p} \int_{n}^{n+1} u^{p q-k p-1}(u-n)^{k p-p} d u \\
& -(2 k)^{p} \int_{n}^{n+1} u^{p q-k p-1}\left|\sum_{r=1}^{n-1}(u-r)^{k-1} r a_{r}\right|^{p} d u .
\end{aligned}
$$

Since the final integral is finite, it follows that

$$
\int_{n}^{n+1} u^{p q+p-1}\left|\frac{d}{d u} C_{k}(u)\right|^{p} d u
$$


is infinite unless $k p-p>-1$, that is, unless $k>1-1 / p$.

The object of this note is to prove the following

TheOREM. For $p \geqslant 1, k>1-1 / p, k \geqslant q-1 / p, \Sigma a_{n}$ is summable $|C, k, q|_{p}$ if and only if it is summable $|R, k, q|_{p}$.

The case $p=1, q=0$, of this theorem has been established by Hyslop [2]. The proof of the theorem is modelled on the one given by Boyd and Hyslop [1] for an analogous result (with $q=0$ ) on strong summability. One of their subsidiary results which we use is :

Lemma. If $\alpha_{r} \geqslant 0, p \geqslant 1, \lambda>1-1 / p$, then

$$
\sum_{n=1}^{N}\left\{\sum_{r=1}^{n} \frac{\alpha_{r}}{(n+1-r)^{\lambda+1}}\right\}^{p} \leqslant K \sum_{n=1}^{N} \alpha_{n}^{p}
$$

where $K$ is independent of $N$ and $\alpha_{r}$.

2. Proof of the theorem. Let $p \geqslant 1, k>1-1 / p, k \geqslant q-1 / p$, and let $n$ be a positive integer.

(i) It follows from an order relation given by Boyd and Hyslop [1, 97], that, for $n<u \leqslant n+1$,

$$
\begin{aligned}
u^{p q+p-1}\left|\frac{d}{d u} C_{k}(u)\right|^{p} & =O\left\{\left(u^{q-k-1 / p} \sum_{r=1}^{n} \frac{r^{k+1}\left|\Delta C_{t}^{(k)}\right|}{(n+1-r)^{k+1}}\right)^{p}\right\} \\
& \quad+O\left\{(u-n)^{k p-p}\left(u^{q-k-1 / p} \sum_{r=1}^{n} \frac{r^{k+1}\left|\Delta C_{r}^{(k)}\right|}{(n+1-r)^{k+1}}\right)^{p}\right\} \\
= & \left.O\left\{\left(1+(u-n)^{k p-p}\right)\right)\left(\sum_{r=1}^{n} \frac{r^{q+1-1 / p}\left|\Delta C_{r}^{(k)}\right|}{(n+1-r)^{k+1}}\right)^{p}\right\}
\end{aligned}
$$

since $k+1 / p-q \geqslant 0$; whence

$$
\int_{n}^{n+1} u^{p q+p-1}\left|\frac{d}{d u} C_{k}(u)\right|^{p} d u=O\left\{\left(\sum_{r=1}^{n} \frac{r^{q+1-1 / p}\left|\Delta C_{r}^{(k)}\right|}{(n+1-r)^{k+1}}\right)^{p}\right\},
$$

since $k p-p>-1$.

It follows, by the lemma, that there is a positive number $K_{1}$ such that

$$
\begin{aligned}
\int_{1}^{\infty} u^{p q+p-1}\left|\frac{d}{d u} C_{k}(u)\right|^{p} d u & =\sum_{n=1}^{\infty} \int_{n}^{n+1} u^{p q+p-1}\left|\frac{d}{d u} C_{k}(u)\right|^{p} d u \\
& \leqslant K_{1} \sum_{n=1}^{\infty} n^{p q+p-1}\left|\Delta C_{n}^{(k)}\right|^{p} .
\end{aligned}
$$

Consequently $\Sigma a_{n}$ is summable $|R, k, q|_{p}$ whenever it is summable $|C, k, q|_{p}$.

(ii) Now let $m$ be the integer such that $m-1 \leqslant k<m$. In virtue of a result established by Boyd and Hyslop [1,99], we find that

$$
\begin{aligned}
n^{a+1-1 / p}\left|\Delta C_{n}^{(k)}\right| & =O\left\{n^{a-k-1 / p} \sum_{r=0}^{n}(n+1-r)^{k-m-2} \int_{r}^{r+1} u^{k+1}\left|\frac{d}{d u} C_{k}(u)\right| d u\right\} \\
& =O\left\{\sum_{r=1}^{n}(n+1-r)^{k-m-2} \int_{r}^{r+1} u^{a+1-1 / p}\left|\frac{d}{d u} C_{k}(u)\right| d u\right\},
\end{aligned}
$$


since $k+1 / p-q \geqslant 0$, and $\frac{d}{d u} C_{k}(u)=0$ for $0<u<1$. Applying now the lemma with

$$
\alpha_{\tau}=\int_{r}^{r+1} u^{q+1-1 / p}\left|\frac{d}{d u} C_{k}(u)\right| d u
$$

and Hölder's inequality, we see that there is a positive number $K_{2}$ such that

$$
\begin{aligned}
\sum_{n=1}^{\infty} n^{p q+p-1}\left|\Delta C_{n}^{(k)}\right|^{p} & \leqslant K_{2} \sum_{n=1}^{\infty}\left(\int_{n}^{n+1} u^{q+1-1 / p}\left|\frac{d}{d u} C_{k}(u)\right| d u\right)^{p} \\
& \leqslant K_{2} \sum_{n=1}^{\infty}\left(\int_{n}^{n+1} u^{p q+p-1}\left|\frac{d}{d u} C_{k}(u)\right|^{p} d u\right)\left(\int_{n}^{n+1} d u\right)^{p-1} \\
& =K_{2} \int_{1}^{\infty} u^{p a+p-1}\left|\frac{d}{d u} C_{k}(u)\right|^{p} d u
\end{aligned}
$$

Hence $\Sigma a_{n}$ is summable $|C, k, q|_{p}$ whenever it is summable $|R, k, q|_{p}$.

The proof of the theorem is thus complete.

\section{REFERENCES}

1. A. V. Boyd and J. M. Hyslop, A definition for strong Rieszian summability and its relation. ship to strong Cesàro summability, Proc. Glasgow Math. Assoc., 1 (1952-3), 94-99.

2. J. M. Hyslop, On the absolute summability of series by Rieszian means, Proc. Edinburgh Math. Soc., 5 (1937-8), 46-54.

3. M. Fekete, Vizsgálatok az absolut summabilis sorokrol, alkalmazással a Direchlet-és Fourier-sorokra, Math. és Termész. Ĺrt., 32 (1914), 389-425.

4. T. M. Flett, Some more theorems concerning the absolute summability of Fourier series and power series, Proc. London Math. Soc., (3), 8 (1958), 357-387.

5. N. Obreschkoff, Sur la sommation absolue des séries de Dirichlet, Comptes Rendus, 186 (1928), 215.

6. N. Obreschkoff, Über die absolute Summierung der Dirichletschen Reihen, Math. Z. 30 (1929), 375-386.

St. Salvator's College

UNTVERSITY of St. ANDREWS 